\title{
A Deliberative Orientation to Governing Carbon Dioxide Removal: Actionable Recommendations for National-Level Action
}

\author{
Amanda C. Borth ${ }^{1 *}$ and Simon Nicholson ${ }^{2}$ \\ ' Department of Communication, George Mason University, Fairfax, VA, United States, ${ }^{2}$ Institute for Carbon Removal Law \\ and Policy, American University, Washington, DC, United States
}

OPEN ACCESS

Edited by:

Rob Bellamy,

The University of Manchester,

United Kingdom

Reviewed by:

Javier Lezaun,

University of Oxford, United Kingdom

Laurie Waller,

University of East Anglia,

United Kingdom

*Correspondence:

Amanda C. Borth

aborth@gmu.edu

Specialty section:

This article was submitted to

Negative Emission Technologies,

a section of the journal

Frontiers in Climate

Received: 22 March 2021

Accepted: 17 June 2021

Published: 22 July 2021

Citation:

Borth AC and Nicholson S (2021) A Deliberative Orientation to Governing Carbon Dioxide Removal: Actionable Recommendations for National-Level

Action. Front. Clim. 3:684209.

doi: 10.3389/fclim.2021.684209
Effective and legitimate governance of carbon dioxide removal (CDR) requires that the needs, interests, and perspectives of those liable to bear the burdens of CDR's effects be present in decision-making and oversight processes. This ideal has been widely recognized in prior academic work. How, though, in a practical sense, is this deliberative aspect of CDR governance to be understood? In this policy brief, we look at the future incorporation of carbon removal pledges into the nationally determined contributions (NDCs) of countries under the Paris Agreement, and we argue for and explore a deliberative orientation when it comes to the inclusion of CDR into country-level climate change response goals. The aim is to provide practical guidance on deliberation as a toolkit and set of practices.

Keywords: carbon dioxide removal (CDR), Paris Agreement, Nationally Determined Contribution (NDC), deliberation, deliberative democracy, communication

\section{INTRODUCTION}

Scientific assessment of the future trajectories and impacts of climate change now suggest that carbon dioxide removal (CDR) must be part of humanity's response to climate change (IPCC, 2018). Drawing down carbon dioxide from the atmosphere at a scale that would help to avoid the worst effects of climate change calls for a range of potential CDR approaches alongside other climate change response options. However, not all CDR options are created equal. Each has its own suite of drawbacks, co-benefits, and questions having to do with appropriate utilization and scale (Morrow et al., 2018). How, then, can governance architectures-and the people working in and around those architectures-juggle technical, social, and environmental considerations to ensure that development and any scaling up of the use of CDR approaches are safe, just, effective, and sustainable?

The starting point for this policy brief is that the governance challenges associated with CDR suggest a role for a set of ideas and approaches often lumped together as deliberation. While significant work has been done on deliberation and CDR via group facilitations, we argue that an expanded role for deliberative thinking is needed to ensure governance frameworks and democratic processes account for societal values and knowledge while also handling conflicting interests in pursuit of the common good (Parkhill et al., 2013; Burns and Flegal, 2015; Bellamy and Lezaun, 2017; Pidgeon, 2021). We make the case that negotiators, specifically, and others who work within governments to construct nationally determined contribution (NDC), generally, ought to take a deliberative orientation-approaching their verbal and written communication by enacting standards of good deliberative practice - to the work of CDR governance. 
We have in mind that CDR looks set to play a more prominent role in the NDCs of parties to the Paris Agreement. The development, negotiation, and implementation of NDCs, in turn, constitute ripe sites for the broader and constructive adoption of deliberative practice. We outline a deliberative orientation centered on the NDCs by: (1) describing the features of CDR uptake that call for deliberative practice; (2) defining deliberation; (3) explaining what deliberation can do for the governance of CDR; and (4) evaluating what deliberation has done thus far for CDR governance. These learnings are used to craft the concept of a deliberative orientation and to offer actionable recommendations on how a deliberative orientation can be used in the further development of country-level climate action pledges that incorporate CDR.

\section{CDR IN THE NDCS: AN OPPORTUNITY FOR A DELIBERATIVE ORIENTATION}

In this opening section, we set the context for this brief by first providing a primer on the NDC process and CDR's current role within it. We then highlight features of CDR's further incorporation into NDCs that call for a deliberative orientation in the process of developing these country-level pledges.

\section{Where CDR Meets the NDCs}

The nationally determined contributions (NDCs) are the mechanism under the Paris Agreement by which countries that are party to the agreement make pledges for climate action. Article 4(2) of the Paris Agreement calls on each party to "prepare, communicate and maintain successive [NDCs] that it intends to achieve" (Paris Agreement, 2015). NDCs are meant to signal and to drive domestic climate action and to be strengthened through time via what is known in the Paris Agreement framework as the "global stocktake". ${ }^{1}$

The potential for countries to bring CDR into NDC commitments is invited by Article 4(1) of the Paris Agreement, with its call for "... a balance between anthropogenic emissions by sources and removals by sinks of greenhouse gases in the second half of this century ...." (Paris Agreement, 2015) However, CDR has, to this point, been largely in the background of Paris Agreement activities. While more than $75 \%$ of the first round of NDCs contained forest sector targets, very few of those targets called expressly for the counting of carbon removals via biological sinks toward country net emissions goals (Sato et al.,

\footnotetext{
${ }^{1}$ Article 14 of the Paris Agreement calls on the Conference of the Parties to "periodically take stock of this Agreement to assess the collective progress toward achieving the purpose of the Agreement," indicates that such a stocktake should occur every five years beginning in 2023, and directs that the outcomes of the stocktake "shall inform Parties in updating and enhancing, in a nationally determined manner, their actions and support." This last point is a supplement to language in Article 4(9), directing each party to "communicate a nationally determined contribution every five years ... and be informed by the outcomes of the global stocktake referred to in Article 14" (Paris Agreement, 2015). The global stocktake and relevant provisions are meant to serve as a rachet mechanism in the agreement, such that the NDCs of each party express greater ambition and lay the path to greater levels of climate action for each party through time.
}

2019, p. 3). Additionally, none of the first round NDCs suggested a planned reliance by any country on engineered carbon removal options or on an ambitious scaling up of non-forest biological CDR pathways.

This, though, looks set to change. Some recent net-zero pledges from countries are giving express reference to CDR options. Switzerland, for instance, has been explicit about a necessary reliance on some amount of technological CDR to meet a net-zero by 2050 target, while the European Union has outlined technological CDR options in the analysis supporting its netzero target setting (European Commission, 2018; The Federal Council, 2020). As further net-zero pledges are made, a sharper focus on the necessary role to be played by CDR approaches can be expected, and, in fact, CDR-relevant domestic policymaking is already very much underway (Schenuit et al., 2021). There has also been a surge of corporate carbon removal pledges which are likely, in time, to inform country-level policy and target setting ${ }^{2}$.

Such announcements raise an important consideration for CDR's future incorporation into NDCs as they speak to how NDCs are created. Each country government has followed its own NDC development process. One of the results of this heterogeneity is that the first- and second-round NDCs, revealed to date, are highly varied in terms of their content, length, and degrees of attention to various climate-relevant subject matters ${ }^{3}$. This represents a general shift produced by the NDCs within international climate negotiations significantly marked by, as Keohane and Oppenheimer (2016) have put it, a movement from a Kyoto-era system of "mandates and simplicity" to a structure premised on "discretion and vagueness" (p. 146). This vagueness is, to some extent, by design, giving individual countries latitude in the establishment and conveyance of climate action priorities. For some countries, though, the vagueness in NDCs signals a set of capacity issues, as governments were required by first-round NDCs, in some instances for the first time, to identify nationallevel climate change mitigation and adaptation targets without an infrastructure or set of processes for the development of such targets (Röser et al., 2020).

Across the variance described above, there are some common opportunities and challenges presented by the likely further incorporation of CDR into NDCs. The case we set out in the remainder of this note is that it is essential, as CDR finds its way more fully into pledges under the Paris Agreement, that more than lip service be given to the art and actions of deliberation. As a starting point, we outline here two features associated with the broader uptake of CDR that suggest the need and give a starting point for the characterization of effective CDR-focused deliberative practice and that direct attention to some of the required steps associated with consideration of CDR in nationallevel climate action and target setting.

\footnotetext{
${ }^{2}$ See the Institute for Carbon Removal Law and Policy's corporate carbon removal action tracker: https://docs.google.com/spreadsheets/d/1vf- uXsf6fo7MuNpPya2Kz82Dxte0hHgtOXimgpRA3c/.

${ }^{3}$ The degree of differentiation in second round NDCs can be expected to be far lower than in the first round, due to the guidance on NDC subject matter and accounting provided by the Paris Rulebook.
} 


\section{Feature 1: CDR Entails Domestic Action Toward International Goals}

Incorporating CDR into NDCs is, at face-value, a countrylevel task; however, it is truly an international endeavor. The chief reason to explore CDR's role in country-level NDCs is in response to global climate change targets set out by the Paris Agreement. This feature-the synergy between domestic actions and international goals-both calls for national-level consultation of international voices when developing NDCs and presents an opportunity for deliberative practices to answer that call.

More precisely, we are pointing out that the CDR component of an individual country's NDC cannot, ultimately, be established without reference to the CDR plans and targets of other countries nor without regard to possible spillover impacts. Scaling CDR projects undertaken largely or fully within a country could conflict with targets developed and actions taken by other countries. For instance, the carbon drawdown potential via afforestation is large, but limited, such that equity considerations ought to be at play in how CDR from afforestation is distributed across NDCs (Pozo et al., 2020). The same can broadly be said among other forms of carbon removal. This suggests a need for efforts by those developing NDCs to work in close consultation with counterparts in other countries, even in the production of targets. A deliberative approach speaks to this need: Enacting the characteristics of deliberative practiceexpressed later in Table 1-may aid those responsible for the establishment of NDCs to bring the perspectives of other countries into conversation with their own when it comes to the roles CDR may play in pursuit of Paris targets.

\section{Feature 2: CDR Interacts With Other Environmental and Social Imperatives}

Tackling climate change is about much more than limiting atmospheric concentrations of greenhouse gases. As Morrow et al. (2020) have noted, when it comes to CDR, "it's not all about the carbon" (at p. 151). The precise actions taken in pursuit of climate goals matter for people and the planet, such that climate action must be structured in ways that account for all dimensions of particular response options-social impacts, technical characteristics, and environmental co-benefits and risks. This suggests a need to keep environmental justice considerations to the fore, ensuring that activities are crafted with benefits and costs to the most vulnerable top of mind, with the practical implication that those liable to be impacted by CDR developments have a strong voice in the creation of those developments. This suggests both a need and an opportunity for a deliberative orientation when it comes to the development of NDCs.

The need is that high-level targets be attentive to the potential distributional and direct impacts of CDR developments. The opportunity comes in the enlisting of a wider array of voices and perspectives in the establishment of NDC targets, including from those likely to be impacted. We have more to say on these points below. At its broadest, the establishment of CDR-specific targets
TABLE 1 | Qualities of good deliberative practice.

\begin{tabular}{|c|c|}
\hline Quality & Description \\
\hline $\begin{array}{l}\text { Guiding } \\
\text { Qualities }\end{array}$ & $\begin{array}{l}\text { Attributes of deliberation that are basic to and undergird all other } \\
\text { qualities of deliberation. }\end{array}$ \\
\hline Mutual respect & $\begin{array}{l}\text { Working to understand one another's motivations, experiences, } \\
\text { and interpretations of reality. }\end{array}$ \\
\hline $\begin{array}{l}\text { Absence of } \\
\text { coercive } \\
\text { power }\end{array}$ & $\begin{array}{l}\text { Addressing and redressing power imbalances. Attempting to } \\
\text { move others against their will should have no place in } \\
\text { deliberation. Rather, those involved ought to open space for } \\
\text { free, equal communication and provide one another with the } \\
\text { resources necessary to have equal opportunity for shared } \\
\text { understanding. }\end{array}$ \\
\hline
\end{tabular}

Core Qualities Attributes of deliberation that set it apart from other forms of communication.

Reason-giving Giving arguments that carefully link premise to conclusion. This quality must accommodate differences in speaking and reasoning (rational arguments, rhetoric, storytelling, etc.) among those from diverse cultural backgrounds. It also entails an emotional commitment to, at minimum, the process of reasoning.

Active listening Listening to others and for previously unheard voices. The listener actively engages with a speaker through verbal communication to check that they understand the speaker's perceptions and experiences that underlie their reason-giving as completely as possible (e.g., eliciting reflexive feedback via clarifying questions) and is attentive to how non-verbal communication may enhance that understanding.

Elevating Attributes of deliberation that are sometimes contested, not Qualities specific to deliberation per se, but enhance its ability to achieve the various goals of deliberation (i.e., arriving at the best answer to a collective problem, advancing democratic principles, etc.).

Clarifying Mapping alternative views and opinions in an effort to better see conflict a range of solutions, and their appraisals, to inform immediate consensus or future decision-making.

Common Exhibiting empathy that enables the consideration of one good another's and greater communities' well-being. This does not orientation negate self-interest.

Accountability Acting on the responsibility - as a decision-maker-to consider, respond to, and incorporate different perspectives into final decisions.

Publicity Ensuring transparency - to the degree possible-so that participants are informed about every step of the process.

Sincerity Demonstrating authenticity in conversations to understand one another, as opposed to purely strategic goal attainment.

These qualities of deliberation continue to be revised, questioned, and contested through development of academic literatures and deliberative practice. This table is not to be viewed as definitive but as a guide toward more deliberative communication across contexts and scales.

in NDCs invites more attention to the climate action roles of nonstate actors and the incorporation of non-state actors into NDC creation processes (Hsu et al., 2019). This suggests coordination and consultation not just with public sector but also private sector entities. Governments can be expected to invest directly in CDR schemes and set the conditions for CDR to emerge (or not) in particular jurisdictions. At the same time, much, and perhaps most, CDR development will be driven by and come from actions by and activities in the private sector. There is a need, presented by the further incorporation of CDR into NDCs, to establish 
dialogue-focused practices that can encompass private sector activities and the implications of those activities for individuals and communities.

In summary, the CDR options that countries are now examining will have direct impacts on a range of peoples and places. CDR demands not just in-country work but also cross-boundary target setting with attendance to a wide variety of potential positive and negative spillover effects. Full consideration of CDR options requires work within countries encompassing an array of potentially impacted actors, from frontline communities to powerful corporations. The undertaking of "stakeholder consultation" is suggested in the first-round NDCs of 118 countries (Khan, 2019). As with CDR commitments, though, precisely what is meant by stakeholder consultation has not been well-specified, and nor have the political challenges associated with identifying and characterizing "stakeholders" been resolved. In what follows we characterize the what, why, and how of a deliberative orientation that can be taken toward country-level CDR commitments, suggesting this orientation can use characteristics of good deliberation to infuse communication, assessment, and evaluation of CDR options at all levels in service of sound CDR governance.

\section{GROUNDING A DELIBERATIVE ORIENTATION: LESSONS FROM DELIBERATIVE DEMOCRATIC THEORY AND CLIMATE ENGINEERING LITERATURES}

\section{What Is Deliberation?}

Deliberation, at its core, refers to mutual communication that is grounded in reason-giving and active listening (Bächtiger et al., 2018; Bächtiger and Parkinson, 2019c). This minimalist definition leaves room for deliberation to take many shapes and occur in many sites at the local, regional, national, and international levels (Bächtiger et al., 2018; Maia, 2018; Setälä and Smith, 2018; Bächtiger and Parkinson, 2019c). Deliberation can take the shape of a deliberative democratic system or an interpersonal interaction: It can occur in an organized mini-public-an institution where a diverse group of citizens are randomly selected to reason about a public concern-or in a mass-media environment (Bächtiger et al., 2018; Maia, 2018; Setälä and Smith, 2018). What matters is that regardless of the shape, site, or level, communication among those involved is rooted in the deliberative corereason-giving and active listening-and strives toward the standards for "good" deliberation, as outlined in Table 1 (Mansbridge, 1999; Burkhalter et al., 2002; Steenbergen et al., 2003; Mansbridge et al., 2010; Dobson, 2014a,b; Bächtiger et al., 2018; Morrell, 2018; Bächtiger and Parkinson, 2019b,c; Scudder, 2020) ${ }^{4}$.

These standards for good deliberation provide a guide for what deliberative engagements ought to strive toward; however,

\footnotetext{
${ }^{4}$ Thank you to Reviewer 1 for their insights regarding Table 1.
}

these standards continue to be questioned and revised as theories of deliberative democracy evolve (Bächtiger et al., 2018) ${ }^{5}$. In Table 1 we draw a distinction between "guiding qualities," "core qualities", and "elevating qualities" of good deliberative practice. The guiding qualities in Table $\mathbf{1}$ are largely accepted and their definitions settled (Steenbergen et al., 2003; Bächtiger et al., 2018). The core qualities in Table 1, by contrast, are essential for constituting communication as deliberative, but, unlike the guiding qualities, their definitions have either evolved significantly (e.g., reason-giving) or are still ill defined (e.g., active listening) (Mansbridge, 1999; Burkhalter et al., 2002; Steenbergen et al., 2003; Bächtiger et al., 2018; Bächtiger and Parkinson, 2019b). When defining those core qualities, we worked to craft a set of robust and concrete definitions given existing literature. The elevating qualities in Table 1 represent qualities that enhance the deliberativeness of an interaction but have and continue to undergo revision: We comprised this cluster of qualities by collecting practices that are routinely cited as ideal for good deliberation and worked to capture their essence (Mansbridge et al., 2010; Bächtiger et al., 2018). As Bächtiger et al. (2018) explain, deliberative democracy_including its ideal qualitiesremains an essentially contested concept. These ideal standards are a normative guide to right action, and their realization in the real-world affords avenues for further research (Black et al., 2013; Bächtiger and Parkinson, 2019a).

\section{Why Deliberation?}

The characteristics of deliberation listed in Table $\mathbf{1}$ are more than a set of abstract definitions: They also represent why deliberation is useful for the development of effective CDR governance. The features of CDR outlined in section CDR in the NDCs: An Opportunity for a Deliberative Orientation above make clear that technical target-setting alone is an insufficient guide to CDR development. CDR will be researched, tested, and deployed in particular social and political contexts. The different qualities of good deliberation can aid those tasked with integrating CDR into NDCs by garnering relevant perspectives, situating CDR development within competing interests and values-sets, and ensuring that CDR decision-making is attentive to the needs of the most vulnerable. The stakes are high, and the decisions made today about CDR will impact individuals and communities tomorrow. The aforementioned qualities and values of deliberation, at minimum, serve as a set of pointers toward best-possible decision-making.

\section{How Experiments in Deliberation Have Advanced Thinking About CDR Governance}

Since the characteristics and values of deliberation can help with navigation of the challenges associated with CDR governance, it is not surprising that there have been significant calls for

\footnotetext{
${ }^{5}$ Bächtiger et al. (2018) provides a useful summary of how these standards for good deliberation have matured and where contestation still exists. Their Table 1.1 Standards for Good Deliberation provided a touchstone for the development of Table 1 in this policy brief.
} 
deliberation in "climate engineering"6 governance and research (Parkhill et al., 2013; Burns and Flegal, 2015; Bellamy and Lezaun, 2017; Pidgeon, 2021). Research in this area can be traced back to calls for public engagement in The Royal Society (2009) report Geoengineering the climate: Science, governance and uncertainty ${ }^{7}$ (Bellamy and Lezaun, 2017). These calls raised the question: How can societies meaningfully engage diverse perspectives in the responsible innovation of climate engineering technologies (Parkhill et al., 2013)? In response, researchers have conducted group, workshop-style deliberative public engagements around the subject matter of climate engineering, particularly in the UK, to: (1) explore public appraisals of these technologies and (2) determine how to best facilitate deliberative exercises to deepen public engagement (Corner et al., 2012; Parkhill et al., 2013; Burns and Flegal, 2015; Bellamy, 2016; Bellamy et al., 2016, 2017; Bellamy and Lezaun, 2017; Cox et al., 2020; Pidgeon, 2021).

This experimental and workshop-based work has significantly advanced thinking about CDR governance by garnering public insights into the risks and uncertainties that CDR options pose (Cox et al., 2020; Pidgeon, 2021). We seek to build on such work by arguing that a broader deliberative orientation ought to be taken into consideration and development of the roles to be played by $\mathrm{CDR}$ in national-level climate strategy. Our intent here, in other words, is to take learnings from experimental and workshop-based work and to apply those learnings in the broader arena constituted by CDR consideration in national-level climate policymaking. In particular, the aforementioned work offers two lessons that can help us do so and broaden the conversation from group deliberation toward a set of insights and strategies with wider application for CDR governance.

\section{Lesson 1: Unframing}

The practice of unframing was coined by Bellamy and Lezaun (2017) and can be a useful tool for practicing a deliberative orientation beyond group facilitations. Framing refers to a way of presenting information about an issue that highlights the salience of a specific aspect of that issue (Wardekker and Lorenz, 2019). Those aspects can be causal interpretationsthe why, who, what, and how of an issue-ways of defining the issue, moral evaluations, and/or recommended solutions (Nisbet, 2009; Swain, 2015; Wardekker and Lorenz, 2019). An example of framing how CDR is defined would be highlighting its naturalness though an analogy: "One technology that we work on acts like an artificial tree by breathing in carbon dioxide from the atmosphere and then storing it underground" (Corner and Pidgeon, 2015, p. 431). We know that different framings of CDR options impact their interpretations as climate change solutions

\footnotetext{
6"Climate engineering" or "geoengineering" was, for a time, used as an umbrella term to describe both CDR and solar radiation management (SRM) climate change response options. The lumping together of CDR and SRM has largely broken down. We support this splitting of SRM and CDR (Jinnah and Nicholson, 2019). Here, we mine older climate engineering governance accounts and more recent accounts that look specifically at CDR governance options for the lessons that can be gleaned concerning deliberative practice.

${ }^{7}$ This report stated, "Public attitudes toward CDR and SRM methods, and public participation in discussion of how development and implementation is managed and controlled, will be critical. Geoengineering methods should be responsible and openly researched, and only deployed by common consent" (The Royal Society, 2009, p. 50).
}

(Corner and Pidgeon, 2015; Campbell-Arvai et al., 2017). It has been recommended that designers of public engagement dialogues recognize what frames they may be imparting on participants and actively avoid introducing those frames so that participants can articulate their own frames of CDR (Bellamy and Lezaun, 2017; Pidgeon, 2021). Doing so enhances the deliberative quality of a group facilitation by opening space for reason-giving. Those involved in CDR governance may also consider making their written and verbal communication more deliberative by recognizing how they themselves frame CDR in their reasongiving, actively listening to understand the frames others use to package CDR, and avoiding imparting their own frames on others.

\section{Lesson 2: Lead With Inquiry}

There are a variety of strategies to elicit reason-giving and encourage active listening in deliberatively oriented exchanges (Polletta and Gardner, 2018). However, one strategy that nearly anyone, not just facilitators, can use to practice the qualities expressed in Table 1 is asking questions. Bellamy and Lezaun (2017) explain how facilitators involved in the Stratospheric Particle Injection for Climate Engineering project (SPICE) workshops steered participants away from defaulting to expert views and toward articulating their own values by asking various iterations of: Why is this important to you? This is a powerful and useful question for opening space for reason-giving and listening. Researchers, practitioners, negotiators, and decisionmakers may consider leading their interactions by (1) asking themselves why certain components of the CDR conversation are important to them to possibly open space for more robust reasongiving, and (2) asking others why certain components of the CDR conversation are important to them, which may encourage listening for understanding with mutual respect. Doing so could enhance the deliberative quality of an interaction and steer us away from bad decisions toward better decisions about CDR.

\section{RECOMMENDATIONS: TAKING A DELIBERATIVE ORIENTATION TO CDR AND THE NDCs}

It is not that deliberation needs to expand to include a fuller account of democratic communication. Quite the reverse: it is that deliberative processes can be seen as a cluster of different, often non-deliberative practices which vary by goals and context without giving up on the idea of core deliberative values (Bächtiger and Parkinson, 2019c, p. 29).

To summarize, we are arguing here for a move away from treating deliberation as a set of formal workshops and experimental conditions and toward the adoption of a deliberative orientation in the range of communications acts that are part of considering the roles CDR might play within the context of NDCs under the Paris Agreement. Deliberation need not only take the shape of a group facilitation in CDR governance, which can be resource intensive and not always appropriate for every decisionmaking context. In addition, deliberation need not only elicit public perceptions and appraisal, which, to date, has tended to produce a unidirectional flow of information from the public 
to decision-makers. Deliberation can also be a part of any instance of communication and include a multi-directional flow of information and perspectives.

We have argued that the features of incorporating CDR into NDCs presents an opportunity for negotiators-and others involved in NDC decision-making-to adopt a deliberative orientation for better CDR governance and better CDR outcomes. We acknowledge that CDR is a highly technocratic arena of climate policy that has the potential to work against the deliberative democratic governance of the climate, but that does not mean that we should not, as a global community, put our best foot forward to work toward more deliberative democratic governance ${ }^{8}$. Here, we offer three overlapping recommendations: Our intent is to take the insights from deliberative theory and lessons from prior deliberation-oriented work outlined above and to marry them to the specific considerations raised by growing interest in CDR options. Note that being overly prescriptive in these recommendations would run somewhat counter to the deliberative orientation we are urging. Deliberative programs and interventions ought best be co-designed with participants, taking account of specific local needs. That said, we have aimed by way of examples and relevant literature to set clear direction for the operationalization of a deliberative orientation.

\section{Recommendation 1: Move From Broad Calls for "Consultation" in NDCs to the Structuring of Deliberative Interactions}

There appears broad acceptance across first-round NDCs of the desirability of "stakeholder consultation." Consultative models of communication tend, though, to produce largely one-way transmission of information from those crafting policies and projects to those experiencing the impacts, with the intent of generating acceptance of a predetermined set of options. In addition, the defining of "stakeholders" is itself a political act, giving access and claim to some while excluding others. A deliberative orientation demands something more. Deliberation, by contrast, means setting up engagements intent on redressing power imbalances and providing the political space for new potential pathways to emerge.

This intent can be expressed directly in NDCs when referencing CDR developments and target-setting, by dropping vague calls for stakeholder consultation in favor of clear, structured plans for deliberative engagement with a full array of impacted individuals and communities. The objective should be the coproduction of goals, projects, and evaluative mechanisms. Such an orientation and commitment to structuring deliberative interactions has been modeled by the 2020 Climate Assembly UK. Six committees of the United Kingdom's House of Commons commissioned this assembly to garner public guidance on how the UK should meet its 2050 target of reaching net-zero greenhouse gas emissions (Climate Assembly UK, 2020). This assembly redressed power imbalances by including 108 members representative of the UK population in the coproduction of principles to guide the UK's path to net-zero and industry

\footnotetext{
${ }^{8}$ We thank Reviewer 2 for this insight as well.
}

specific recommendations (Climate Assembly UK, 2020). A different variant of a deliberative orientation can be seen developing in the United States, for instance, with the Biden administration's elevation of environmental justice as a new fulcrum for environmental action and decision-making. The administration is working to establish a White House Advisory Justice Council and an interagency process to work with local communities and leaders on the identification and redressing of environmental injustices. Carbon removal and the potential roles to be played by carbon removal in US national-level climate planning, including via the NDCs, will be structured by this new attention to environmental justice as outcome and process. More specifically, planning for the testing and siting of new carbon removal schemes backed by US federal government spending will, according to officials, require deliberative community engagement with environmental justice principles to the fore ${ }^{9}$.

Another way to open space for the coproduction of knowledge and appraisals is to act on the "unframing" lesson outlined above. This means avoiding prematurely imposing frames in NDC language, supporting documents, and accompanying processes, but instead seeking actively to create space for fruitful reason-giving, active listening, and understanding toward more equitable burden sharing. Part of deliberative planning means recognizing that CDR developments will have impacts for equitable burden sharing beyond state boundaries even if CDR activities themselves are confined within a particular state's borders. There is also a clear need to work with private sector actors. This suggests that deliberative communications strategies must be designed with cross-border dimensions and a full array of interested actors in mind.

\section{Recommendation 2: Ensure That People Are Considered Along With the Technical Dimensions of CDR Developments}

CDR targets are typically expressed in technical terms, prioritizing metrics like dollars per ton of carbon dioxide sequestered and technical scalability constraints. A deliberative orientation invites moving beyond technical considerations in the setting of CDR targets to more fully consider, evaluate, and incorporate the human dimensions of CDR developments. The "leading with inquiry" insight is instructive. Asking questions of those who will be impacted by the implementation of nationallevel targets and working actively to uncover and engage with the values of those impacted can help a weaving of deliberative practice into target-setting toward a richer understanding of what CDR means for the lives it may affect. This type of inquiry can assist, as CDR options are brought more fully into the NDCs, with the paying of more particular attention to establishment of plausible social co-benefits and risks along with deliberative means to more fully characterize such co-benefits and risks and to evaluate them over time.

One place to embed this kind of thinking and structuring is directly within the expert institutions that are largely responsible for shaping the roles that carbon removal will play within the

${ }^{9}$ This assertion is based on conversations between one of the authors and officials inside the US Department of Energy. 
broader sweep of climate policy ${ }^{10}$. A deliberative orientation, engaging with a full array of potentially impacted actors to define "good" carbon removal and to measure its development across social, technical, and environmental dimensions, corresponds with the kind of reflexive "responsible assessment" that Beck and Mahony (2018a,b) have called for in relation to the Intergovernmental Panel on Climate Change (IPCC). Beck and Mahony note that expert bodies like the IPCC have tended to this point to foster a policy-neutral stance, facilitated by creating and policing artificial boundaries between science creation and policymaking. Science creation is never, though, a politically neutral act, and a too-narrow self-definition of the IPCC's role serves to mask the political implications of the IPCC's assessment work. A "responsible assessment" would in part entail clear identification and incorporation of the broader social and environmental implications of technical findings and modeled pathways incorporating carbon removal. This demands that scientific assessment bodies widen the voices enlisted, the approaches utilized, and the concerns and interests examined. National scientific bodies and policy processes concerned with the creation of NDCs and longer-term country-level climate strategies would do well to embrace such advice.

\section{Recommendation 3: Ensure a Correspondence Between Project-Level Questions and Country-Level Targets}

Country-level target setting for CDR, focusing on the roles that CDR can play in meeting broad society-wide net emissions targets, can seem divorced from the kinds of questions that should be asked of individual CDR projects. A deliberative orientation suggests that even in the highest-level goal setting, the implications for people and the planet of the growth of particular kinds of CDR projects ought to be given consideration. Another way of saying this is that multiscalar thinking is needed in the incorporation of CDR into NDCs. Attentiveness to the needs and voices of a full range of stakeholders can take CDR from abstract representation in an emissions pathways figure to the reality of CDR as a set of activities with demonstrable effects on actual people. However, attentiveness to these voices does not mean just listening. It requires more. It requires (1) eliciting voices and (2) actively listening to what they have to say. The "lead with inquiry" notion shows that negotiators and others can ask stakeholders about their values and perspectives and actively work to understand them.

Said differently, deliberation is often conveyed as a kind of panacea, with the implication that more talk will produce better outcomes. This is not the case. Instead, deliberation is best

${ }^{10}$ Thanks to Reviewer 1 for this insight.

\section{REFERENCES}

Bächtiger, A., Dryzek, J. S., Mansbridge, J., and Warren, M. E. (eds.). (2018). "Deliberative democracy: an introduction," in The Oxford Handbook of Deliberative Democracy (Oxford: Oxford University Press), 1-34. understood as a guide and set of practices that are basic to, but not supplanting of, good governance. We have argued here that a deliberative orientation should be adopted by those working on national-level CDR policymaking and incorporation into climate action pledges. Such an orientation seems appropriate given the complexity of the decisions that need to be taken around $\mathrm{CDR}$ and the implications for societies and environments of differently constituted CDR portfolios. Deliberation becomes real with careful attention to equitable burden sharing, a prioritizing of people over technical characteristics alone of CDR options, and a structured attentiveness to the impacts of big plans on real people.

\section{CONCLUSION}

Ultimately, this policy brief marries theory, a secondary account of empirical research, and practice to provide actionable recommendations that decision-makers and others can implement immediately in their day-to-day work. We have developed general, high-level recommendations by standing on the shoulders of deliberative democratic theory and the innovative work previously conducted on CDR deliberation, communication, and public engagement. It is our hope that this policy brief makes the sometimes lofty and idealistic notion of deliberation into something more tangible and accessible to anyone working in CDR governance, not just those who specialize in facilitating group deliberations. Geden (2016), however, provides us, as researchers, a sobering reminder that we are not expert negotiators in the NDC process and "should resist the temptation to act like political entrepreneurs peddling [our] advice..." (p. 796). In the spirit of deliberation, we put forth our understanding of deliberation in CDR governance and encourage the broadening of this conversation to include a wider array of perspectives. In the end, by taking deliberation seriously and expanding our visualization of what it can be and do for CDR governance, our global community has a better chance at steering CDR decision-making away from the bad and toward the common good.

\section{AUTHOR CONTRIBUTIONS}

$A B$ was lead author on this paper, defined deliberation, created Table 1, drew lessons from previous literature on CDR and deliberation, and led the development of a deliberative orientation as a concept. $\mathrm{AB}$ and $\mathrm{SN}$ co-developed the ideas presented in this policy brief. $\mathrm{SN}$ examined the relevance of $\mathrm{CDR}$ in the NDCs and conceived the features in section CDR in the NDCs: An Opportunity for a Deliberative Orientation and led the formation of the actionable recommendations. All authors contributed to the article and approved the submitted version.

Bächtiger, A., and Parkinson, J. (2019a). "Assessing and measuring deliberativeness," in Mapping and Measuring Deliberation: Towards a New Deliberative Quality (Oxford: Oxford Scholarship Online), 132-151.

Bächtiger, A., and Parkinson, J. (2019b). "Locating 'deliberativeness," in Mapping and Measuring Deliberation: Towards a New Deliberative Quality (Oxford: Oxford Scholarship Online), 104-131. 
Bächtiger, A., and Parkinson, J. (2019c). "Unpacking deliberation," in Mapping and Measuring Deliberation: Towards a New Deliberative Quality (Oxford: Oxford Scholarship Online), 19-44.

Beck, S., and Mahony, M. (2018a). The IPCC and the new map of science and politics. Wiley Interdisc. Rev. Clim. Change 9:e547. doi: 10.1002/ wcc. 547

Beck, S., and Mahony, M. (2018b). The politics of anticipation: the IPCC and the negative emissions technologies experience. Glob. Sustain. 1:e8. doi: $10.1017 /$ sus.2018.7

Bellamy, R. (2016). A sociotechnical framework for governing climate engineering. Sci. Technol. Hum. Values 41, 135-162. doi: 10.1177/01622439155 91855

Bellamy, R., Chilvers, J., and Vaughan, N. E. (2016). Deliberative mapping of options for tackling climate change: citizens and specialists 'open up' appraisal of geoengineering. Public Understand. Sci. 25, 269-286. doi: $10.1177 / 0963662514548628$

Bellamy, R., and Lezaun, J. (2017). Crafting a public for geoengineering. Public Understand. Sci. 26, 402-417. doi: 10.1177/09636625156 00965

Bellamy, R., Lezaun, J., and Palmer, J. (2017). Public perceptions of geoengineering research governance: an experimental deliberative approach. Glob. Environ. Change 45, 194-202. doi: 10.1016/j.gloenvcha.2017.06.004

Black, L. W., Burkhalter, S., Gastil, J., and Stromer-Galley, J. (2013). "Methods for analyzing and measuring group deliberation," in The Sourcebook for Political Communication Research: Methods, Measures, and Analytical Techniques, eds E. P. Bucy and R. L. Holbert (New York, NY: Routledge), 323-345.

Burkhalter, S., Gastil, J., and Kelshaw, T. (2002). A conceptual definition and theoretical model of public deliberation in small face-to-face groups. Commun. Theory 12, 398-422. doi: 10.1111/j.1468-2885.2002.tb00276.x

Burns, W. C. G., and Flegal, J. A. (2015). Climate geoengineering and the role of public deliberation: a comment on the US National Academy of Sciences' recommendations on public participation. Climate Law 5, 252-294. doi: 10.1163/18786561-00504006

Campbell-Arvai, V., Hart, P. S., Raimi, K. T., and Wolske, K. S. (2017). The influence of learning about carbon dioxide removal (CDR) on support for mitigation policies. Clim. Change 143, 321-336. doi: 10.1007/s10584-017-2005-1

Climate Assembly UK (2020). The Path to Net Zero. London: House of Commons. Available online at: https://www.climateassembly.uk/recommendations/index. html

Corner, A., and Pidgeon, N. (2015). Like artificial trees? The effect of framing by natural analogy on public perceptions of geoengineering. Clim. Change 130, 425-438. doi: 10.1007/s10584-014-1148-6

Corner, A., Pidgeon, N., and Parkhill, K. (2012). Perceptions of geoengineering: public attitudes, stakeholder perspectives, and the challenge of 'upstream' engagement. WIREs Clim. Change 3, 451-466. doi: 10.1002/wcc.176

Cox, E., Spence, E., and Pidgeon, N. (2020). Public perceptions of carbon dioxide removal in the United States and the United Kingdom. Nat. Clim. Chang. 10, 744-749. doi: 10.1038/s41558-020-0823-z

Dobson, A. (2014a). "Learning about listening," in Listening for Democracy: Recognition, Representation, Reconciliation (New York, NY: Oxford University Press), 48-80.

Dobson, A. (2014b). "Deliberative and dialogic democracy," in Listening for Democracy: Recognition, Representation, Reconciliation (New York, NY: Oxford University Press), 81-108.

European Commission (2018). In-Depth Analysis in Support of the Commission Communication COM(2018) 773: A Clean Planet for all a European Long-Term Strategic Vision for a Prosperous, Modern, Competitive and Climate Neutral Economy. Brussels.

Geden, O. (2016). The Paris Agreement and the inherent inconsistency of climate policymaking. WIREs Clim. Change 7, 790-797. doi: 10.1002/wcc.427

Hsu, A., Brandt, J., Widerberg, O., Chan, S., and Weinfurther, A. (2019). Exploring links between national climate strategies and non-state and subnational climate actions in nationally determined contributions (NDCs). Clim. Policy 20, 443-457. doi: 10.1080/14693062.2019.1624252

IPCC (2018). "Summary for policymakers," in Global Warming of $1.5^{\circ} \mathrm{C}$. An IPCC Special Report on the Impacts of Global Warming of $1.5^{\circ} \mathrm{C}$ above PreIndustrial Levels and Related Global Greenhouse Gas Emission Pathways, in the
Context of Strengthening the Global Response to the Threat of Climate Change, Sustainable Development, and Efforts to Eradicate Poverty, eds V. MassonDelmotte, P. Zhai, H.-O. Pörtner, D. Roberts, J. Skea, P. R. Shukla. Available online at: https://www.ipcc.ch/site/assets/uploads/sites/2/2019/05/SR15_SPM_ version_report_LR.pdf

Jinnah, S., and Nicholson, S. (2019). Introduction to the symposium on 'geoengineering: governing solar radiation management'. Env. Polit. 28, 385-396. doi: 10.1080/09644016.2019.1558515

Keohane, R. O., and Oppenheimer, M. (2016). Paris: beyond the climate dead end through pledge and review? Politics Govern. 4, 142-151. doi: 10.17645/pag.v4i3.634

Khan, F. (2019). NDC score card: measuring the nationally determined contributions (NDCs) under the Paris Agreement. 123. M-RCBG Associate Working Paper Series (Cambridge, MA: Mossavar-Rahmani Center for Business and Government, Harvard Kennedy School).

Maia, R. C. M. (2018). "Deliberative media." in The Oxford Handbook of Deliberative Democracy, eds A. Bächtiger, J. S. Dryzek, J. Mansbridge, and M. E. Warren (Oxford University Press), 348-364.

Mansbridge, J. (1999). "Everyday talk in the deliberative system," in Deliberative Politics: Essays on Democracy and Disagreement, ed S. Macedo (New York, NY: Oxford University Press), 211-242.

Mansbridge, J., Bohman, J., Chambers, S., Estlund, D., Føllesdal, A., Fung, A., et al. (2010). The place of self-interest and the role of power in deliberative democracy. J. Polit. Philos. 18, 64-100. doi: 10.1111/j.1467-9760.2009.00344.x

Morrell, M. E. (2018). "Listening and deliberation," in The Oxford Handbook of Deliberative Democracy, eds A. Bächtiger, J. S. Dryzek, J. Mansbridge, and M. E. Warren (Oxford, UK: Oxford University Press), 237-250.

Morrow, D. R., Buck, H. J., Burns, W. C. G., Nicholson, S., and Turkaly, C. (2018). Why Talk About Carbon Removal? Washington, DC: Institute for Carbon Removal Law and Policy, American University.

Morrow, D. R., Thompson, M. S., Anderson, A., Batres, M., Buck, H. J., Dooley, K., et al. (2020). Principles for thinking about carbon dioxide removal in just climate policy. One Earth 3, 150-153. doi: 10.1016/j.oneear.2020.07.015

Nisbet, M. C. (2009). Communicating climate change: why frames matter for public engagement. Environ. Sci. Policy Sustain. Dev. 51, 12-23. doi: 10.3200/ENVT.51.2.12-23

Paris Agreement (2015). Conclusion Date: December 12, 2015. United Nations Treaty Series Online, Registration no. I-54113.

Parkhill, K., Pidgeon, N., Corner, A., and Vaughan, N. (2013). "Deliberation and responsible innovation: a geoengineering case study," in Responsible Innovation: Managing the Responsible Emergence of Science and Innovation in Society (West Sussex, UK: John Wiley and Sons, Ltd.), 219-239.

Pidgeon, N. (2021). Engaging publics about environmental and technology risks: frames, values and deliberation. J. Risk Res. 24, 28-46. doi: $10.1080 / 13669877.2020 .1749118$

Polletta, F., and Gardner, B. G. (2018). "The forms of deliberative communication," in The Oxford Handbook of Deliberative Democracy, eds A. Bächtiger, J. S. Dryzek, J. Mansbridge, and M. E. Warren (Oxford: Oxford University Press), 70-85.

Pozo, C., Galán-Martín, Á., Reiner, D. M., Mac Dowell, N., and Guillén-Gosálbez, G. (2020). Equity in allocating carbon dioxide removal quotas. Nat. Clim. Chang. 10, 640-646. doi: 10.1038/s41558-020-0802-4

Röser, F., Widerberg, O., Höhne, N., and Day, T. (2020). Ambition in the making: analysing the preparation and implementation process of the nationally determined contributions under the Paris Agreement. Clim. Policy 20, 415-429. doi: $10.1080 / 14693062.2019 .1708697$

Sato, I., Langer, P., and Stolle, F. (2019). Enhancing NDCs: opportunities in the forest and land-use sector. Working Paper (Washington, DC: World Resources Institute).

Schenuit, F., Colvin, R., Fridahl, M., McMullin, B., Reisinger, A., Sanchez, D. L., et al. (2021). Carbon dioxide removal policy in the making: assessing developments in 9 OECD cases. Front. Clim. 3, 1-22. doi: $10.3389 /$ fclim.2021.638805

Scudder, M. F. (2020). "Listening for difference in democracy," in Beyond Empathy and Inclusion: The Challenge of Listening in Democratic Deliberation (New York, NY: Oxford Scholarship Online), 145-174.

Setälä, M., and Smith, G. (2018). "Mini-publics and deliberative democracy," in The Oxford Handbook of Deliberative Democracy, eds A. Bächtiger, J. 
S. Dryzek, J. Mansbridge, and M. E. Warren (Oxford: Oxford University Press), 300-314.

Steenbergen, M. R., Bachtiger, A., Sporndli, M., and Steiner, J. (2003). Measuring political deliberation: a discourse quality index. Comp. Eur. Politics 1, 21-48. doi: 10.1057 /palgrave.cep.6110002

Swain, K. A. (2015). "Mass media roles in climate change mitigation," in Handbook of Climate Change Mitigation and Adaptation, eds M. Lackner, B. Sajjadi, and W. Y. Chen (New York, NY: Springer), 162-195.

The Federal Council (2020). Climate Change: Federal Council Adopts Report on Negative $\mathrm{CO}_{2}$ Emissions. Available online at: https://www.admin.ch/gov/en/ start/documentation/media-releases.msg-id-80271.html (accessed March 22, 2021).

The Royal Society (2009). Geoengineering the Climate: Science, Governance and Uncertainty. London: The Royal Society. Available online at: https:// royalsociety.org/ /media/royal_society_content/policy/publications/2009/ 8693.pdf
Wardekker, A., and Lorenz, S. (2019). The visual framing of climate change impacts and adaptation in the IPCC assessment reports. Clim. Change 156, 273-292. doi: 10.1007/s10584-019-0 $2522-6$

Conflict of Interest: The authors declare that the research was conducted in the absence of any commercial or financial relationships that could be construed as a potential conflict of interest.

Copyright $\odot 2021$ Borth and Nicholson. This is an open-access article distributed under the terms of the Creative Commons Attribution License (CC BY). The use, distribution or reproduction in other forums is permitted, provided the original author(s) and the copyright owner(s) are credited and that the original publication in this journal is cited, in accordance with accepted academic practice. No use, distribution or reproduction is permitted which does not comply with these terms. 